\title{
Pola Beli Konsumen Menggunakan Algoritma FP-Growth untuk Rekomendasi Promosi pada Aneka Jaya Motor
}

\author{
Junta Zeniarja $^{1}$, Kurniawan Ridwan Surohardjo ${ }^{2}$, Agus Winarno ${ }^{3}$ \\ Fakultas Ilmu Komputer, Universitas Dian Nuswantoro \\ Jl. Imam Bonjol No. 207 Semarang, telp. (024) 3569196 \\ e-mail: 1junta@dsn.dinus.ac.id, ${ }^{2}$ kurwawandev@gmail.com, ${ }^{3}$ agus.winarno@dsn.dinus.ac.id
}

Diterima: 24 Februari 2021; Disetujui: 30 April 2021

\begin{abstract}
Abstrak
Suatu informasi yang tepat dapat menciptakan dan menetapkan strategi bisnis dalam meningkatkan penjualan melalui teknologi yang dapat mempengaruhi perdagangan jual beli barang dengan data informasi yang dihasilkan dapat dikalkulasi secara rinci dan akurat. Pada toko Aneka Jaya Motor Semarang terpicu akan hal tersebut untuk tuntutan persaingan. Salah satu solusi berupa target promosi barang. Untuk penentuan barang mana yang layak untuk dilakukan promosi maka dibuatnya sistem aplikasi rekomendasi keputusan promosi menggunakan teknik data mining asosiasi pada algoritma FP-Growth, fungsinya untuk menemukan barang yang sering dibeli secara bersamaan oleh konsumen. Data yang digunakan berupa data transaksi dengan jumlah total yang digunakan 501 data. Hasil yang didapat dengan muncul 1 aturan yaitu jika konsumen membeli part busi maka membeli part oli dengan minimum support sebesar $10 \%$ dan minimum confidence sebesar $35 \%$. Lift ratio yang didapat sebesar 1 sehingga valid sesuai aturan yang dihasilkan.
\end{abstract}

Kata kunci: data mining, promosi, asosiasi, fp-growth, lift ratio

\begin{abstract}
A piece of appropriate information can create and establish a business strategy in increasing sales through technology that can affect the trade-in buying and selling goods with the data information generated can be calculated in detail and accurately. At Aneka Jaya Motor Semarang, this was triggered by the demand for competition. One solution is a product promotion target. For determining which items are feasible for promotion, the application of a promotional decision recommendation system is made using data mining techniques associated with FPGrowth algorithms, its function is to find items that are often purchased simultaneously by consumers. Data used in the form of transaction data with the total amount used 501 data. The results obtained by appearing 1 rule is if consumers buy spark plug parts then buy oil parts with minimum support of $10 \%$ and minimum confidence of 35\%. The lift ratio obtained is 1 so that valid rules are generated.
\end{abstract}

Keywords: data mining, promotion, association, fp-growth, lift ratio

\section{PENDAHULUAN}

Bisnis adalah suatu bidang yang mempunyai potensi nilai informasi sangat tinggi. Dari informasi tersebut bisa berpengaruh terhadap strategi dalam persaingan bisnis. Ketepatan dan validnya suatu informasi dapat menciptakan inovasi dan meningkatkan ketepatan dalam pemilihan strategi bisnis, sehingga diharapkan dapat meningkatkan penjualan dan menjamin 
kelangsungan bisnis dalam jangka panjang. Dalam perihal ini, data yang mudah diakses, pas serta efesien amat diperlukan oleh pelakon bidang usaha [1]. Teknologi yang semakin maju juga dapat mempengaruhi perdagangan dalam proses jual beli suatu barang. Dengan adanya teknologi yang semakin maju dapat membantu proses jual beli suatu barang tersebut dapat dilakukan dengan cepat, sehingga dengan data yang dihasilkan dapat di kalkulasi dengan rinci dan akurat.

Objek yang digunakan adalah pada toko Aneka Jaya Motor di kota Semarang yang bergerak dalam bidang bisnis penjualan sparepart motor secara ritel dan melayani jasa servis motor dengan kondisi berat maupun ringan. Sistem penjualan di Aneka Jaya Motor dilakukan dengan cara pelanggan datang ke toko, kemudian menanyakan ketersediaan barang yang dibeli. Apabila barang tersebut tersedia selanjutnya dilakukan proses transaksi. Persaingan perdagangan di daerah tersebut memicu pengelola untuk menciptakan inovasi dan strategi bisnis demi meningkatkan volume transaksi penjualan. Pada transaksi yang dilakukan, setiap bulannya pengelola toko merekap nota dan di alihkan pada Microsoft Excel. Semakin banyak transaksi penjualan yang masuk setiap harinya, menyebabkan pengelola merasa kesulitan di dalam menemukan barang yang sering di beli secara berbarengan oleh pelanggan.

Pada pendekatan teknik data mining Asosiasi terdapat beberapa algoritma yaitu Apriori dan $\mathrm{FP}$-Growth [2]-[6]. Penggalian data yang besar untuk menemukan pola asosiasi dibutuhkan algoritma yang tepat, antara lain FP-Growth. FP-Growth ialah perkembangan dari algoritma Apriori [1]. Association Rule bertujuan untuk menemukan aturan asosiatif suatu kombinasi item yang memenuhi syarat minimum dari nilai support dan nilai confidence. Market Basket Analysis ialah teknik di dalam data mining didalam menemukan produk-produk yang dibeli oleh pelanggan secara bersamaan berdasarkan dari transaksi penjualan terhadap pelanggan tersebut. Pada penelitian yang telah dilakukan oleh Asrul Abdullah dengan judul Rekomendasi Paket Produk Guna Meningkatkan Penjualan dengan Metode FP-Growth, dapat disimpulkan bahwa hasil dari studi tersebut adalah sisem yang dikembangkan dapat digunakan sebagai rekomendasi paket produk sesuai dengan kebutuhan dari seluruh konsumen berdasarkan perhitungan tingkat frekuensi item yang telah dibeli oleh konsumen, sehingga berdampak pada peningkatan penjualan [7]. Dari pernyataan tersebut maka teknik data mining Asosiasi serta algoritma FP-Growth ini dapat diterapkan pada toko Aneka Jaya Motor yang memiliki data transaksi penjualan yang besar.

Informasi yang dihasilkan dari association rule yaitu berupa nilai minimum support dan minimum confidence, dimana akan digunakan menjadi acuan oleh pengelola toko Aneka Jaya Motor dalam mengambil keputusan. Semakin besar nilai minimum support dan minimum confidence maka akan semakin akurat dan ringkas kriteria yang dihasilkan dari hubungan antar barang yang satu dengan barang yang lain. Jika nilai yang dihasilkan dari association rule melebihi syarat yang sudah ditentukan, maka hasilnya dapat digunakan sebagai acuan dalam pengambilan keputusan promosi dan diharapkan dapat meningkatkan penjualan sparepart motor.

\section{METODE PENELITIAN}

\subsection{Association}

Association (asosiasi) ialah salah satu teknik Data Mining yang bertujuan untuk menentukan atribut yang sering keluar secara bersamaan pada suatu waktu [4], [8], [9]. Hasil dari teknik Data Mining asosiasi ini berupa aturan pola asosiasi (association rule) yaitu untuk mengukur hubungan antara dua atau lebih atribut, sehingga ditemukannya aturan asosiasi antara suatu kombinasi item [10]. Tujuan dari dilakukannya association rule adalah menentukan nilai support dan confidence yang kedepannya dapat dijadikan acuan untuk kelayakan keputusan.

Dari item yang digunakan, untuk mendapatkan nilai supportnya maka digunakan rumus pada persamaan (1) [11]:

$$
\text { Support }(A)=\frac{\text { jumlah transaksi yang mengadung item } A}{\text { total transaksi }}
$$


Selanjutnya untuk mencari nilai support dari dua item dapat menggunakan rumus pada persamaan (2) :

$$
\operatorname{Support}(A, B)=P(A \cap B)=\frac{\text { jumlah transaksi mengandung } A \text { dan } B}{\text { total transaksi }}
$$

Sedangkan untuk mendapatkan nilai confidence maka menggunakan rumus pada persamaan (3) :

$$
\text { Confidence }(A \rightarrow B)=P(A \mid B)=\frac{\text { jumlah transaksi mengandung } A \text { dan } B}{\text { jumlah transaksi mengandung } A}
$$

\subsection{FP-Tree}

FP-Tree adalah bentuk penyimpanan informaso yang dimampatkan. FP-Tree dibentuk dengan metode menempatkan tiap data rekaman transaksi ke dalam setiap jalur khusu di dalam FP-Tree, sebab dalam setiap transaksi yang sudah ditempatkan bisa jadi terdapat transaksi lain yang mempunyai item yang serupa, alhasil jalurnya membolehkan untuk saling menimpa. Semakin banyak data transaksi yang mempunyai item yang serupa maka proses pemampatan dengan bentuk data $F P$-Tree juga menjadi efisien [12], [13].

Pembangunan FP-Tree dibagi menjadi tiga langkah utama sebagai berikut :

a. Melakukan scanning pada sekumpulan data untuk memastikan jumlah support dari masing masing item.

b. Menghapus data yang tidak digunakan, kemudian menciptakan order list secara menurun dari item yang sering dan terbanyak muncul.

c. Melakukan scanning pada sekumpulan data dengan memutuskan satu transaksi pada suatu waktu untuk menciptakan FP-Tree. Pada sebuah transaksi yang khas akan membuat lintasan baru dan node baru dengan perhitungan dimulai dari 1.

\subsection{Algoritma FP-Growth}

FP-Growth ialah algoritma yang memastikan sekumpulan data yang sering keluar dalam sebuah himpunan data [14]. Algoritma ini pengembangan dari Apriori dengan perbedaan dari scanning database dan akurasi aturannya. FP-Growth melaksanakan scanning database sebanyak dua kali, dimana scanning pertama semua item yang frequent dan jumlah support berasal diurutkan dari support terbesar dalam setiap transaksi. Pada scanning kedua, item di setiap transaksi digabung menjadi FP-Tree dan item (node) yang muncul di transaksi yang berbeda dihitung, kemudian setiap node yang berhubungan dengan item dan jumlahnya. Node dengan link yang sama dihubungkan oleh pointer yang disebut node-link. Tahapan dasar dalam FP-Growth mempunyai tingkatan pokok yaitu Conditional Pattern Base, Conditional FP-Tree dan Frequent Pattern.

Algoritma FP-Growth ini memiliki tahapan pembentukkan seperti Conditional Pattern Base, Conditional FP-Tree, Frequent Pattern Generated atau Frequent Itemset. Berikut tahapan penelitian dalam menghasilkan association rule dengan algoritma FP-Growth:

a. Preprocessing Data

Tahap ini merupakan tahapan untuk menyeleksi data yang digunakan sebelum dilakukannya proses perhitungan association rule menggunakan algoritma FP-Growth. Beberapa tahapan dari preprocessing data sebagai berikut :

i. Menyeleksi data setiap transaksi penjualan sparepart yang terjual lebih dari 1 barang.

ii. Melakukan redudansi data transaksi yang terjual kurang dari 1 barang.

iii. Menghilangkan atribut (variable) yang tidak digunakan.

iv. Mentransformasikan data menjadi format tertentu untuk dilakukannya proses data mining.

b. Menetapkan nilai minimum support dan confidence.

c. Pembentukkan prioritas itemset pada data transaksi dengan melakukan penjumlahan frekuensi dari setiap item sesuai syarat minimum support.

d. Pembetukan FP-Tree, dengan dilakukannya scanning pada data transaksi penjualan sparepart. 
e. Proses pembuatan Conditional Pattern Base yang berisi lintasan prefix dan FP-Tree.

f. Proses pembuatan Conditional FP-Tree dimana memiliki nilai support count nilainya lebih dari satu, sehingga menghasilkan frequent itemset atau frequent pattern generated.

g. Association rule dari data transaksi penjualan sparepart ditemukan dengan perhitungan dari nilai support, confidence dan lift ratio.

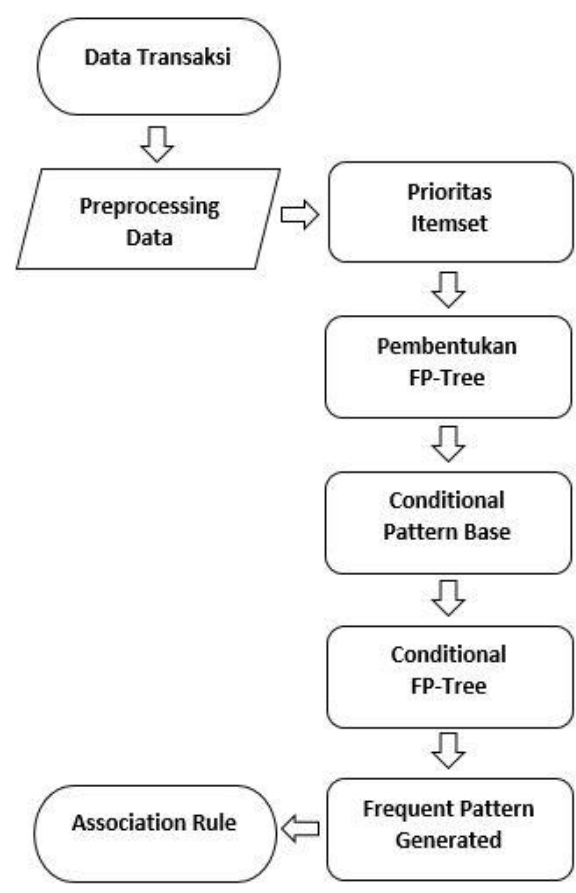

Gambar 1. Langkah FP-Growth

\subsection{Lift Ratio}

Lift ratio merupakan alat ukur penting dalam metode asosiasi. Fungsi yang dimiliki adalah mengukur valid atau tidaknya suatu alat ukur (nilai support dan confidence) agar dapat dipercaya akurasinya. Sebuah itemset dinyatakan valid apabila akurasi pada lift ratio > 1 [15]. Untuk mengukur akurasinya, lift ratio dapat membandingkan antara confidence untuk suatu aturan terhadap benchmark confindence. Rumus yang digunakan untuk perhitungan adalah persamaan (4).

$$
\text { Lift Ratio }=\frac{\text { confidence }(A, B)}{\text { benchmark confidence }(A, B)}
$$

\section{HASIL DAN PEMBAHASAN}

Hasil penelitian ini berupa aturan asosiasi dari data transaksi sebanyak 501 data transaksi yang telah dilakukan transformarsi data. Penelitian dibangun dengan model perangkat lunak yaitu Prototype dan menggunakan algoritma $\mathrm{FP}$-Growth. Rumus yang digunakan adalah nilai support dan confidence. Sedangkan untuk mengukur valid atau tidaknya suatu aturan menggunakan rumus lift ratio. Dalam perancangan aplikasi yang dibuat diimplementasikan pada aplikasi website dengan menggunakan bahasa pemrograman PHP native. Pada pengujian aplikasi menggunakan Black Box Testing.

\subsection{Pengembangan Aplikasi}

Prototype merupakan suatu teknik untuk mengumpulkan suatu informasi tertentu. 
Informasi tersebut perihal kebutuhan - kebutuhan informasi pelanggan secara cepat, sehingga membutuhkan pengembangan aplikasi dengan waktu yang cepat. Kemudian protipe akan dievaluasi dan diuji oleh pelanggan dan dilakukannya perbaikan atau perubahan sesuai dengan kebutuhan pengembangan aplikasi hingga kebutuhan yang diinginkan oleh pelanggan sesuai dan terpenuhi [16].

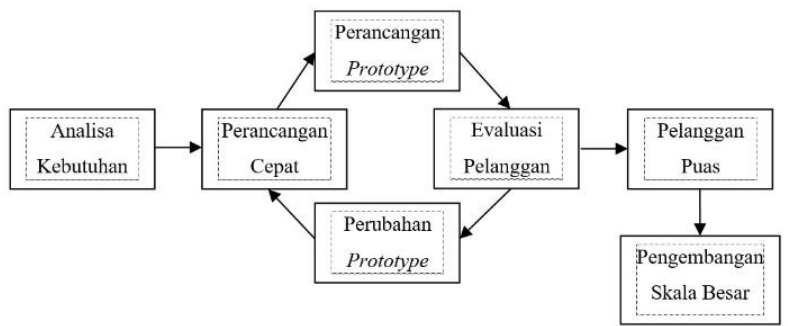

Gambar 2 Model Prototype

Pada penelitian ini diterapkan dengan tahapan sebagai berikut:

1. Menganalisa kebutuhan yang ada. Pada tahap ini peneliti melakukan survey ke toko Aneka Jaya Motor dengan melakukan wawancara kepada pihak pengelola untuk mengetahui masalah yang sedang di alami oleh toko maupun pemilik toko.

2. Melakukan perancangan cepat merupakan tahapan yang dilakukannya perancangan mengenai kebutuhan apa saja yang dibutuhkan pada sistem.

3. Pembangunan prototype merupakan implementasi dari perancangan cepat.

4. Evaluasi akan dilakukan oleh pihak pengelola toko Aneka Jaya Motor terhadap pembangunan prototype yang telah dibuat. Dari tahapan ini dapat diketahui apakah prototype telah sesuai dengan kebutuhan yang diinginkan.

5. Perubahan prototype akan dilakukan jika terjadi kebutuhan yang diinginkan belum terpenuhi dan sesuai.

6. Pengembangan skala besar, jika tidak ada perubahan maka langkah selanjutnya peneliti akan mengembangkan sistem prototype yang telah di setujui.

\subsection{DFD (Data Flow Diagram)}

DFD merupakan gambaran tentang masukkan - proses - keluaran dari suatu sistem yang melibatkan obyek - obyek data mengalir ke dalam sistem, kemudian ditransformasikan oleh elemen - elemen pemrosesan sehingga hasil obyek - obyek data tersebut mengalir keluar dari sistem. DFD pada dasarnya direpresntasikan menggunakan tanda panah, entitas, proses, data flow dan data store. Diagram yang dibentuk berawal dari DFD level 0. DFD level 0 tersebut memiliki cabang setiap prosesnya pula. Perancangan pada penelitian ini menggunakan konteks diagram dan DFD level 0 sebagai berikut:

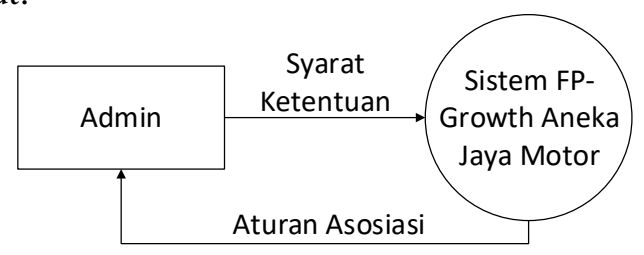

Gambar 3. Konteks Diagram

Konteks diagram diatas menggambarkan keseluruhan yang mewakili seluruh proses. Dalam hal ini admin sebagai pengguna bertujuan langsung untuk menganalisa dan mengetahui hasil dari aturan asosiasi dari syarat ketentuan yang dilakukan, yaitu berupa minimum support, minimum confidence dan jumlah transaksi. 


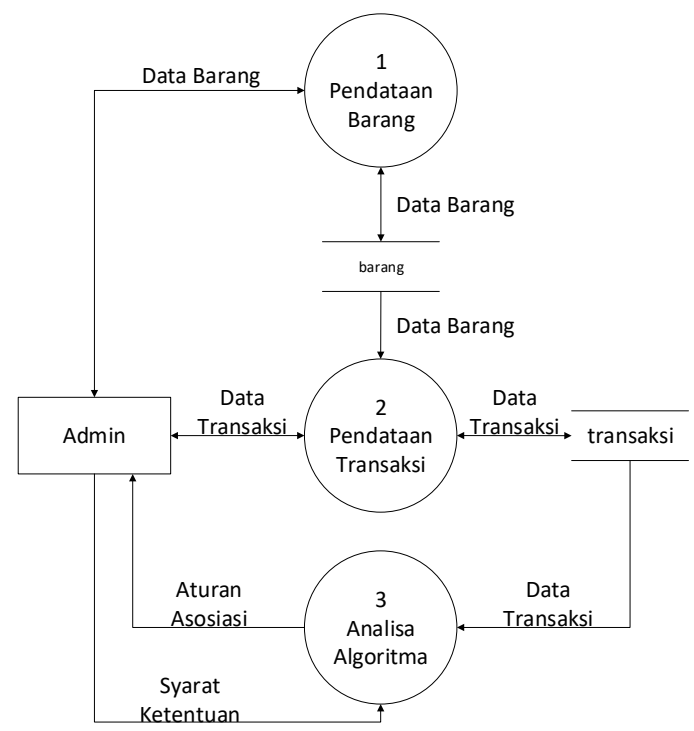

Gambar 4. DFD Level 0

Diagram diatas adalah DFD level 0 yang merupakan uraian dari konteks diagram. Dalam diagram tersebut menunjukkan admin sebagai pengguna dapat melakukan proses pendataan pada data barang dan data transaksi, serta analisa alogirtma. Pada proses pendataan barang yang dilakukan adalah dengan melakukan input, edit dan delete data barang. Pada proses pendataan transaksi yang dilakukan adalah dengan melakukan input, edit dan delete data transaksi. Sedangkan pada proses analisa algoritma yang menggunakan FP-Growth, dapat dilakukannya input syarat ketentuan berupa minimum support, minimum confidence dan jumlah transaksi sehingga dari proses tersebut dapat menghasilkan aturan asosiasi.

\subsection{Hasil Analisa Data}

Data yang diperlukan untuk dieksekusi ke dalam sistem setelah dilakukannya transformasi data dengan 501 data transaksi. Dari aplikasi yang dijalankan, didapatkan hasil aturan asosiasi dari algoritma FP-Growth untuk menemukan item yang sering dibeli secara bersamaan oleh pembeli. Berikut hasil dari aturan asosiasi yang muncul dengan nilai input minimum support sebesar 10\%, minimum confidence sebesar $35 \%$ dan jumlah transaksi sebesar 501 yang terlihat pada gambar 5:

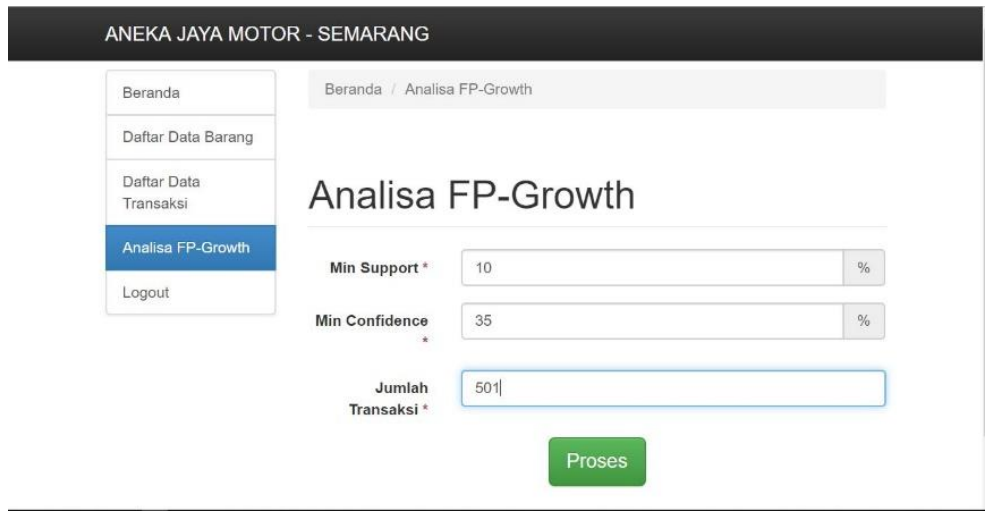

Gambar 5. Analisa Algoritma FP-Growth 


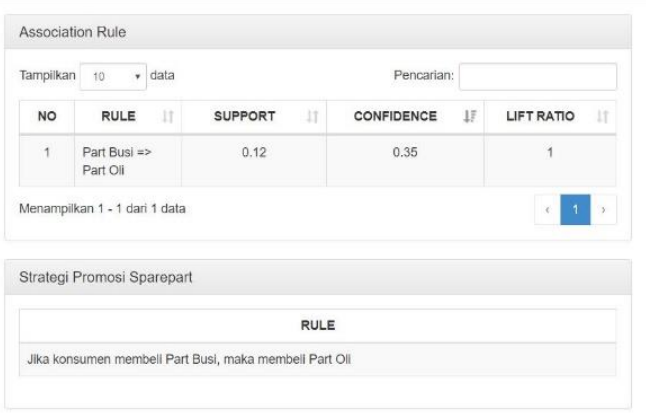

Gambar 6. Hasil Aturan Asosiasi

Dari gambar 6, hasil aturan yang didapat dapat disimpulkan ke dalam strategi promosi bahwa, jika konsumen membeli Part Busi maka membeli Part Oli. Dengan nilai support sebesar 0,12, minimum confidence sebesar 0,35 dan lift ratio sebesar 1 .

\section{KESIMPULAN}

Berdasarkan dari hasil penelitian dan pembahasan dengan pengolahan data transaksi dapat disimpulkan bahwa data transaksi Aneka Jaya Motor dapat diolah dengan menggunakan algoritma FP-Growth pada aplikasi, sehingga dapat berjalan dengan baik dan sesuai tujuan yang diharapkan. Dengan data transaksi yang didapat dan dilakukannya transformasi data, data transaksi menjadi 501 transaksi dengan dilakukannya pengelompokkan atau pengkategorian data barang. Hasil yang didapat dengan menggunakan data transaksi tersebut pada aplikasi analisa $F P$ Growth berupa satu aturan yaitu jika konsumen membeli part busi maka membeli part oli dengan minimum support sebesar $10 \%$ dan minimum confidence sebesar $35 \%$. Dari hasil satu aturan yang didapat yaitu jika konsumen membeli part busi maka membeli part oli (part busi => part oli) dapat dijadikan strategi promosi penjualan sparepart motor.

\section{SARAN}

Saran untuk penelitian kedepan, bisa menggunakan data yang lebih besar yaitu dengan menggunakan data transaksi yang lebih banyak. Menggunakan varian jenis data barang yang lebih sedikit agar terciptanya aturan asosiasi yang lebih banyak. Menggunakan proses fitur upload data barang pada menu daftar data barang dan upload data transaksi pada daftar data transaksi agar lebih praktis. Pihak toko selaku pengguna agar dapat melakukan pemeliharaan aplikasi secara terus menerus.

\section{DAFTAR PUSTAKA}

[1] S.Kasus and P.T.Rosalia, "Sistem Rekomendasi Pemesanan Sparepart Dengan Algoritma Fp-Growth," pp. 6-7, 2016.

[2] W.N.Ismail, M.M.Hassan, and H.A.Alsalamah, "Context-Enriched Regular Human Behavioral Pattern Detection from Body Sensors Data," IEEE Access, vol. 7, no. 1, pp. 33834-33850, 2019.

[3] O.Stit, J.Riffi, A.Yahyaouy, and H.Tairi, "Comparative Study of Different Association Rule Methods," in Colloquium in Information Science and Technology, CIST, 2018, vol. 2018-Octob, pp. 323-327. 
[4] Islamiyah, P.L Ginting, N.Dengen, and M.Taruk, "Comparison of Priori and FP-Growth Algorithms in Determining Association Rules," in ICEEIE 2019 - International Conference on Electrical, Electronics and Information Engineering: Emerging Innovative Technology for Sustainable Future, 2019, pp. 320-323.

[5] M.M. Hasan and S.Zaman Mishu, "An Adaptive Method for Mining Frequent Itemsets Based on Apriori and FP Growth Algorithm," in International Conference on Computer, Communication, Chemical, Material and Electronic Engineering, IC4ME2 2018, 2018, pp. $1-4$.

[6] F.Ren, Z.Pei, and K.Wu, "Selection of satisfied association rules via aggregation of linguistic satisfied degrees," IEEE Access, vol. 7, pp. 91518-91534, 2019.

[7] A.Abdullah, "Rekomendasi Paket Produk Guna Meningkatkan Penjualan Dengan Metode FP-Growth," vol. 4, no. 1, pp. 21-26, 2018.

[8] M.Fauzy, K.R.Saleh W, and I.Asror, "Penerapan Metode Association Rule Menggunakan," J. Ilm. Teknol. Inf. Terap., vol. II, no. 2, pp. 221-227, 2016.

[9] M.Kadafi, "Penerapan Algoritma FP-GROWTH untuk Menemukan Pola Peminjaman Buku Perpustakaan UIN Raden Fatah Palembang," Matics, vol. 10, no. 2, p. 52, 2019.

[10] N.A.Hasibuan, N Silalahi, S.D.Nasution, D.U.Sutiksno, H.Nurdiyanto, and E.Buulolo, "Implementasi Data Mining Untuk Pengaturan Layout Minimarket Dengan Menerapkan Association Rule," vol. 4, no. 4, pp. 6-11, 2017.

[11] L.W.Basalamah and N.Ransi, "Implementasi Algoritma Frequent Pattern Growth Pada Aplikasi Retail Berbasis Java," vol. 3, no. 1, pp. 67-80, 2017.

[12] T. P. Hong, C. Y. Lin, W.M.Huang, K.S.M.Li, L.S.L.Wang, and J.C.W.Lin, "Using Tree Structure to Mine High Temporal Fuzzy Utility Itemsets," IEEE Access, vol. 8, pp. 153692-153706, 2020.

[13] I.Astrina, M.Z. Arifin, and U.Pujianto, "Penerapan Algoritma FP-Growth dalam Penentuan Pola Pembelian Konsumen pada Kain Tenun Medali Mas," Matrix J. Manaj. Teknol. dan Inform., vol. 9, no. 1, pp. 32-40, 2019.

[14] E. Faisal, J. Zeniarja, and D.A.N. Sa'adah, "Pola Beli Konsumen menggunakan Algoritma FP-Growth untuk Rekomendasi Promosi penjualan pada Batik Nadya Pekalongan," in SeNTIK - STMIK JAKARTA STI\&K, 2017.

[15] D.Fitriati, "Implementasi Data Mining untuk Menentukan Kombinasi Media Promosi Barang Berdasarkan Perilaku Pembelian Pelanggan Menggunakan Algoritma Apriori," in Annual Research Seminar 2016, 2016, vol. 2, no. 1, pp. 472-480.

[16] A.Irawan, Rudianto, and R.Desiana, "Prototype Sistem Informasi Bursa Kerja pada Universitas Serang Raya,” J. Sensi Strateg. Educ. Inf. Syst., vol. 7, no. 1, pp. 36-52, 2021. 